\title{
Comparison of Lipopolysaccharide and Outer Membrane Protein- Lipopolysaccharide Extracts in an Enzyme-Linked Immunosorbent Assay for the Diagnosis of Brucella ovis Infection
}

\author{
J. I. RIEZU-BOJ. ${ }^{1}$ I. MORIYÓN. ${ }^{*}$ J. M. BLASCO, ${ }^{2}$ C. M. MARÍN, ${ }^{2}$ AND R. DIAZ ${ }^{1}$ \\ Departamento de Microbiología, Universidad de Navarra, 31080 Pamplona, ${ }^{1}$ and Centro Regional de Investigación y \\ Desarrollo Agrario-03, Zaragoza. ${ }^{2}$ Spain
}

Received 31 October 1985/Accepted 10 February 1986

\begin{abstract}
Brucella ovis hot saline extracts and petroleum ether-chloroform-phenol lipopolysaccharide were compared in an enzyme-linked immunosorbent assay for the diagnosis of $B$. ovis ram epididymitis. Hot saline extracts detected greater numbers of infected rams. Chemical characterization of the antigens showed that, although both contained lipopolysaccharide, hot saline extracts also contained outer membrane proteins. These proteins were active as antigens in Western blot tests with sera of infected rams, and therefore they explained the better diagnostic results obtained with hot saline extracts. However, compared with lipopolysaccharide, hot saline extracts showed a higher degree of cross-reactivity with sera from smooth $B$. melitensis-infected animals. This observation might be explained by the presence of $B$. ovis outer membrane proteins in hot saline extracts which lack the specificity necessary for serological identification of the Brucella species present.
\end{abstract}

Brucella ovis is the causative agent of infectious ram epididymitis, a major animal disease in most sheep-raising countries. Diagnosis of this disease is based on palpation to determine whether epididymitis exists, bacteriological examination of semen, and serological tests. However, since some infected rams do not show evidence of epididymitis and may shed the organisms intermittently, serological tests are more useful (4).

Serological diagnosis of this infection is usually performed by the complement fixation test with sonicated or unfractionated hot saline (HS) extracts of whole B. oris cells as antigens (2). However, it has been shown that in the complement fixation test both false-positive and false-negative reactions occur (26), and other alternative tests for the diagnosis of $B$. ovis ram epididymitis have been described. Myers et al. (24) compared complement fixation and double gel diffusion (DGD) with HS rough cell extracts (7) and found similar results with both tests. More recently, several researchers have investigated the use of the enzyme-linked immunosorbent assay (ELISA) to improve both the sensitivity and specificity of the serological diagnosis of $B$. ovis infection in rams $(1,6,10,25,27,31,34)$.

With the exception of the work of Afzal et al. (1), characterization of the antigenic extracts used in ELISA has not been presented. However, such characterization seems necessary for the following reasons. First, $B$. olis is not the only Brucella species that infects rams, and serological responses to $B$. melitensis also exist. Second, there exists immunological cross-reactivity between some antigens of smooth and rough Brucella species (8), and accordingly serological tests with uncharacterized antigenic preparations cannot be assumed to be specific for $B$. oris. Third, in contrast to $B$. melitensis, $B$. ovis is always in a rough state. Thus, although lipopolysaccharide (LPS) is the major antigen involved in serological diagnosis of diseases caused by smooth brucellae $(9,29)$, this may not be the case in infections caused by $B$. ovis. Outer membrane (OM) proteins, LPS, and also cytoplasmic proteins are antigens

* Corresponding author. whose relative importance in $B$. ovis infections should be established to optimize diagnostic tests.

In this work, we present the characterization of two antigenic extracts currently used for the diagnosis of $B$. ovis infection in rams. Antibody responses to the antigenic components in such extracts were studied and compared for the differentiation of $B$. ovis and $B$. melitensis infections in sheep.

\section{MATERIALS AND METHODS}

Bacterial strains, growth conditions, and cell fractionation. The characteristics and growth conditions of $B$. ovis REO198 have been described elsewhere $(8,17)$. Exponentially growing bacteria were disintegrated by being shaken with glass beads in an MSK-Braun cell homogenizer, and the cell envelope fraction was obtained by ultracentrifugation and characterized on the basis of total protein and LPS content, the presence of NADH oxidase and succinic dehydrogenase, and lack of malic dehydrogenase as described before (23). A fraction rich in OM proteins was prepared by sequential detergent extraction of cell envelopes, first with Sarkosyl and then with Zwittergent 316 as described previously (23). The extract was then delipidated with chloroform-ethanol $(1: 2)$, solubilized in $10 \mathrm{mM}$ Tris hydrochloride [pH 6.8]-0.7 M $\beta$-mercaptoethanol-10\% glycerol, and stored at $4^{\circ} \mathrm{C}$.

Antigenic preparations. $B$. ovis $\mathrm{HS}$ extracts were obtained by suspending viable cells in saline and heating at $100^{\circ} \mathrm{C}$ for $15 \mathrm{~min}(7)$. After removal of cell debris $(15,000 \times g, 30 \mathrm{~min})$, the extract was ultracentrifuged $(100,000 \times g, 5 \mathrm{~h})$, and the pelleted material was suspended in distilled water, dialyzed at $4^{\circ} \mathrm{C}$ against three changes of 100 volumes each of distilled water, and lyophilized. In addition, acetone-dried cells were extracted with petroleum ether-chloroform-phenol (PCP) and, after flash evaporation of chloroform-petroleum ether, PCP-rough LPS (RLPS) was precipitated by saturating the phenol phase with water as described by Galanos et al. (11). Complexes of bovine serum albumin (BSA) and PCP-RLPS were prepared by solubilization of both components in $\mathrm{H}_{2} \mathrm{O}$-triethylamine and removal of the latter under vacuum (12). 
Analytical methods. Protein was determined by the method of Lowry et al. (21) with BSA as the standard. The LPS marker, 2-keto-3-deoxyoctulosonic acid, was measured as described by Warren (33), with modifications described previously (23). RNA was determined by the orcinol reaction (14).

Sodium dodecyl sulfate (SDS)-polyacrylamide gel electrophoresis was performed as described by Laemmli (19). Molecular weight (MW) standards were phosphorylase $b$ $(94,000[94 \mathrm{~K}])$, BSA $(67 \mathrm{~K})$, Escherichia coli OmpF $(38 \mathrm{~K})$, carbonic anhydrase $(30 \mathrm{~K})$, soybean trypsin inhibitor $(21 \mathrm{~K})$, and lysozyme (14K). Gels were stained with Coomassie blue.

Immunological methods. Immunoelectrophoresis was performed in agarose-Veronal as described elsewhere (8). For DGD, the $1 \%$ agarose gel contained $10 \% \mathrm{NaCl}$ and borate (pH 8.3) as a buffer (3). When PCP-RLPS was used in gel precipitation, its solubilization was assisted by either sonication immediately before immunoelectrophoresis or addition of a few microliters of triethylamine. For ELISA, the antigens were coupled to polystyrene plates by overnight incubation of PCP-RLPS or HS extract (both at $10 \mu \mathrm{g}$ [dry weight] per $\mathrm{ml}$ ) in carbonate buffer. The plates were then washed three times with $20 \mathrm{mM}$ phosphate-buffered saline (pH 7.2) containing $0.05 \%$ Tween 20 , and twofold serial dilutions of sera were made in phosphate-buffered saline-Tween. After $1 \mathrm{~h}$ of incubation at $37^{\circ} \mathrm{C}$, the unbound antibody was removed with three washes of phosphatebuffered saline-Tween, and peroxidase-conjugated rabbit anti-sheep immunoglobulin $\mathrm{G}$ (heavy- and light-chain specificity; Nordic Immunological Laboratories, Tilburg, Holland) was added. Incubation was carried out for $1 \mathrm{~h}$ at $37^{\circ} \mathrm{C}$, the plates were washed again, and the substrate was added (20). 5-Amino-2-hydroxybenzoic acid- $\mathrm{H}_{2} \mathrm{O}_{2}$ was used as the substrate. The reaction was assessed colorimetrically (450 $\mathrm{nm}$ ) with a spectrophotometer (Titertek Multiscan; Flow Laboratories, Inc., McLean, Va.). The mean and standard deviation of the optical density (OD) were calculated for the dilution showing the greatest difference between positive and negative controls and used to estimate the ELISA OD distribution in the population as described by Heck et al. (16).

Western blots of SDS-polyacrylamide gel electrophoresis were performed by the method of Burnette (5) with the conjugate described above and 4-chloro-1-naphthol as the substrate (15). Anti-HS extract sera were obtained after hyperimmunization of rabbits with eight intramuscular 1-mg doses of extract.

Sera. The following groups of sera were used. (i) Noninfected controls were sera from 36 Brucella-free rams. (ii) $B$. ovis-infected controls were sera from 36 rams whose semen was culture positive. (iii) $B$. melitensis-infected controls were sera from 36 ewes with infection demonstrated bacteriologically. (iv) Suspected animals were 69 rams belonging to flocks in which $B$. ovis had been isolated. They were divided into two subgroups: 22 animals with palpable epididymitis and 47 without such symptoms. None of these 69 animals was positive by the Rose Bengal and complement fixation standard tests for $B$. melitensis infection.

\section{RESULTS}

The results of the chemical characterization of PCP and HS extracts are presented in Table 1 . It can be seen that, whereas PCP extracts contained almost no protein, this component made up to $50 \%$ of the product obtained by the HS method. In agreement with these data, PCP extracts
TABLE 1. Chemical composition of $B$. ovis antigenic extracts obtained by the HS or PCP extraction method ${ }^{a}$

\begin{tabular}{lcccc}
\hline Method & $\begin{array}{c}\% \\
\text { Protein }\end{array}$ & $\begin{array}{c}\% \\
\text { KDO }^{b}\end{array}$ & $\begin{array}{c}\% \\
\text { RNA }\end{array}$ & $\begin{array}{c}\% \\
\text { Yield }^{c}\end{array}$ \\
\hline HS & $44-50$ & 0.43 & 8.6 & $0.9-2.7$ \\
PCP & $0.5-0.8$ & 2.75 & 10.6 & $1.4-2.2$ \\
\hline
\end{tabular}

${ }^{a}$ When included, ranges represent the highest and lowest values obtained in an analysis of five different batches of extracts.

${ }^{b} \mathrm{KDO}, 2$-keto-3-deoxyoctulosonic acid.

${ }^{c}$ Percentage of cell dry weight.

contained about seven times more 2-keto-3-deoxyoctulosonic acid than did HS extracts. By immunoelectrophoresis with rabbit anti-HS serum, both HS and sonicated PCP extracts developed a major line (Fig. 1) with the shape and mobility characteristic of RLPS (7), and a line of total identity was observed by DGD with either this serum or sera from infected animals (data not shown). These results showed that, in spite of the different protein contents, both preparations shared RLPS as the major antigenic component.

SDS-polyacrylamide gel electrophoresis and Coomassie blue staining identified several proteins in the HS extract, among which a band of an apparent MW close to $25 \mathrm{~K}$ was the most conspicuous one (Fig. 2A, lane 2). Proteins of similar MW were also present in detergent extracts enriched with OM proteins (Fig. 2A, lane 1), and by Western blot it was found that the antiserum to $B$. ovis $\mathrm{HS}$ extracts reacted with the $25 \mathrm{~K}$ protein of the $\mathrm{HS}$ extracts and with its homologous OM protein (Fig. 2B). Furthermore, the same antiserum reacted strongly with other proteins $(21 \mathrm{~K}$ to $14 \mathrm{~K})$ present in both HS and OM preparations (Fig. 2B), despite the fact that they were hardly visible in Coomassie bluestained gels of HS extracts (Fig. 2A, lane 2). None of the above methods revealed the presence of proteins in PCP extracts, in which RLPS was demonstrated by Western blot (Fig. 2C, lane 3) but not by Coomassie blue staining (Fig. 2A, lane 3). Thus, PCP extracts are referred to as PCP-RLPS.

The antigenic extracts described above were compared as diagnostic reagents in an ELISA for detection of $B$. ovis infection in rams by ELISA. In preliminary experiments with sera from control groups 1 and 2, maximal differences in OD were obtained with the $1 / 100$ dilution for either antigenic extract. These same experiments showed that negative controls had a background higher than expected, but this problem could not be solved by varying the conditions of the ELISA or using different sera (rabbit, cow) or proteins (casein, BSA) as blocking agents. It is possible that unspecific binding of antibody to the brucella surface antigens used in the ELISA could explain this background, as reported by Schurig et al. (30) for rough $B$. abortus. Using the 1/100 dilution, we determined the distribution of the OD in ELISA

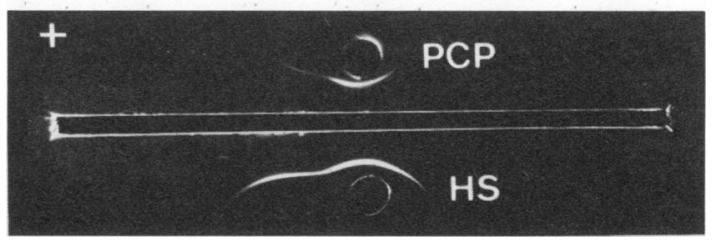

FIG. 1. Immunoelectrophoretic analysis of $B$. ovis PCP-RLPS (5 $\mathrm{mg} / \mathrm{ml})$ and $\mathrm{HS}$ extracts $(10 \mathrm{mg} / \mathrm{ml})$ with anti-HS serum. 


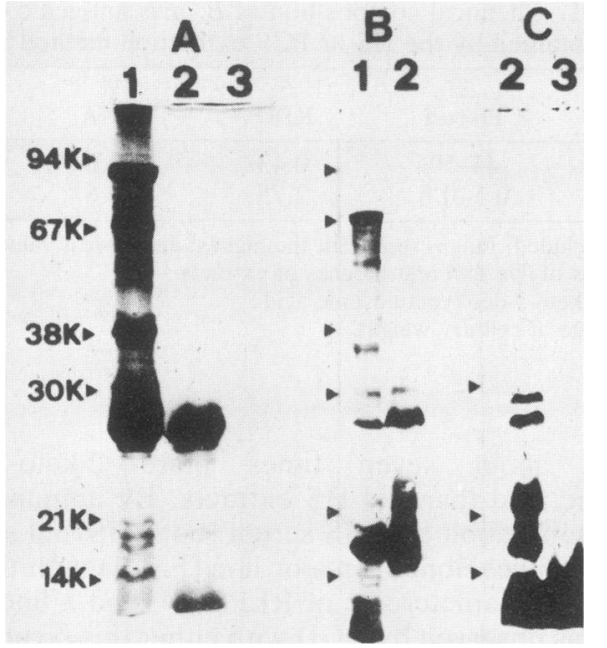

FIG. 2. SDS-polyacrylamide gel electrophoresis (A) and Western blot analysis with anti-HS extract serum (B) or serum from an infected ram (C) of (lanes): 1 , OM protein extracts of B.ovis; 2 , HS extract; and 3, PCP-RLPS. The arrowheads indicate the positions of MW markers in the SDS gel and nitrocellulose sheets.

in healthy and infected populations (Fig. 3). This method was preferred because it allows one to know the probability with which the diagnosis is made for a given OD (16). For instance, for an OD of 0.660 the PCP-RLPS ELISA (Fig. 3A) would detect $95.5 \%$ of the infected (semen culture positive) animals (95.5\% sensitivity) but also $5 \%$ of healthy animals (95\% specificity). With the HS extract and an OD of 0.520

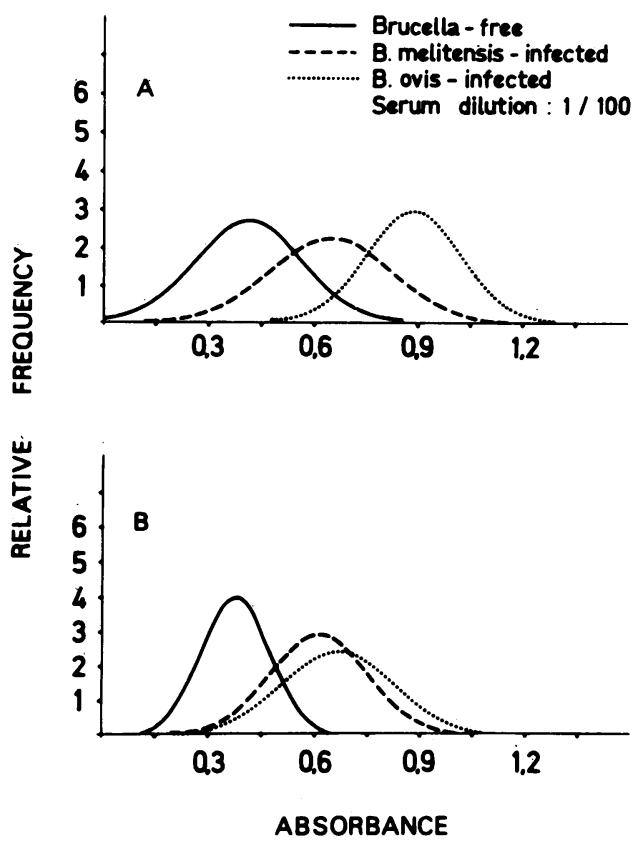

FIG. 3. Distribution of the OD ( $1 / 100$ dilution) of the ELISA with PCP-RLPS (panel A) and HS-extracts (panel B) in Brucella-free rams, $B$. melitensis-infected ewes, and $B$. ovis-infected rams. The means and standard deviations of the groups tested were: (PCPRLPS [panel A]) Brucella free, $0.412 \pm 0.150 ; B$. melitensis infected, $0.646 \pm 0.176 ; B$. ovis infected, $0.889 \pm 0.135$; and (HS extract [panel B]) Brucella free, $0.383 \pm 0.098 ; B$. melitensis infected, 0.612 $\pm 0.137 ; B$. ovis infected, $0.675 \pm 0.160$.
TABLE 2. Results of ELISA (PCP and HS) and DGD (HS) with 69 animals from flocks in which $B$. ovis had been isolated (group 4)

\begin{tabular}{lcccc}
\hline \multirow{2}{*}{ Symptoms } & \multirow{2}{*}{$\begin{array}{c}\text { Total } \\
\text { no. of } \\
\text { animals }\end{array}$} & \multicolumn{3}{c}{ No. of animals positive by: } \\
\cline { 3 - 5 } & 22 & ELISA & & DGD \\
\cline { 3 - 5 } & & 17 & 21 & 21 \\
\hline $\begin{array}{l}\text { Palpable } \\
\text { epididymitis }\end{array}$ & 47 & 27 & 36 & 40 \\
None & & 27 & HS \\
\hline
\end{tabular}

a Animals positive by ELISA were defined as those producing an OD of 0.660 (95.5\% sensitivity with 5\% false-positive reactors) with PCP-RLPS or $0.520(83.4 \%$ sensitivity with $8 \%$ false-positive reactors) with HS in the $1 / 100$ dilution (Fig. 3).

(Fig. 3B), the sensitivity of the test would be $83.4 \%$ (semen culture-positive animals detected) with $8 \%$ false-positive reactions ( $92 \%$ specificity). These results did not differ significantly with three different batches tested.

The serological response of the suspected animals (group 4) was studied with both PCP-RLPS and HS extracts by either ELISA or DGD (Table 2). It can be seen that the proportion of suspected rams detected by either PCP-RLPS ELISA or HS ELISA was higher in the subgroup with symptoms of epididymitis. In addition, the number of rams positive by $\mathrm{HS}$ was always higher than the number of PCP-RLPS-positive ones. Also, no animal was both positive by PCP-RLPS and negative by HS extracts.

Figure 2C shows the result of the Western blot analysis of the antigens used in the ELISA with the serum of one of the rams with bacteriologically proven $B$. ovis infection. It can be seen that this serum contained antibody to the antigenic determinants of both PCP-RLPS and HS extracts, and this result was also obtained with sera from nine other rams tested. An alternative role of OM proteins in HS extracts, such as their acting as LPS carriers that could favor reactions with LPS-specific antibodies, was also considered. However, when PCP-RLPS coupled to BSA as a carrier was tested in both ELISA and DGD, the results did not differ from those obtained with the uncoupled antigen.

Finally, the ability of the HS or PCP-RLPS ELISA to differentiate $B$. ovis infections from those caused by $B$. melitensis was tested with sera from ewes in which infection by the latter species had been demonstrated (group 3). There was considerable overlapping between the OD plots of $B$. melitensis- and $B$. ovis-infected animals with both PCPRLPS and HS (Fig. 3). With HS, overlapping was almost complete.

\section{DISCUSSION}

The results presented in this work demonstrate that when B. ovis RLPS is obtained by the HS method (7) the final extract is heavily contaminated with OM proteins. The observation that contamination of LPS preparations with OM proteins is affected by the method of extraction has also been made with other bacteria (13). Verstreate et al. (32) have classified the Brucella OM proteins present in Sarkosyl-Zwittergent extracts in three distinct MW ranges, i.e., $88 \mathrm{~K}$ to $94 \mathrm{~K}$ (group 1 ), $35 \mathrm{~K}$ to $40 \mathrm{~K}$ (group 2), and $25 \mathrm{~K}$ to $30 \mathrm{~K}$ (group 3). The MW of the major OM protein(s) present in the HS extract strongly suggests that it corresponds to group 3. The same authors (32) have shown that the amino acid composition of group 3 resembles that of $E$. coli OmpA, an OM protein which is known to interact strongly with LPS (22). The interaction between RLPS and OM proteins in the 
HS extract must be very strong, because attempts to separate the $25 \mathrm{~K}$ protein from LPS (2-keto-3-deoxyoctulosonic acid marker) by either ultracentrifugation or gel filtration under a variety of conditions were unsuccessful (results not shown). It may also be significant that, when examined by the Sarkosyl-Zwittergent extraction method, B. ovis $\mathrm{OM}$ is rich in group 3 proteins ( 28 ; this work).

The role of the HS OM proteins in ELISA was evident when the results obtained with HS and PCP-RLPS extracts in the group of suspected animals were compared (Table 2). In addition to the fact that antibody reaction with the OM proteins was shown directly by Western blot (Fig. 2C), the only explanation for the differences observed is that the OM proteins present in HS extracts carry antigenic determinants active in the ELISA.

The same results also suggest that, in infections caused by B. ovis, OM proteins play a role as antigens as important as that of LPS. Although it has been shown that LPS is the major antigen in infections caused by smooth Brucella species $(9,29), B$. ovis is permanently rough. It is known that in rough bacteria OM proteins are more exposed on the cell surface than in smooth strains (22), and accordingly an important role as surface antigens can be postulated for the OM proteins in rough bacteria. This hypothesis is supported by the findings presented in this report.

In contrast to HS extracts, PCP-RLPS did not contain significant amounts of protein, by either Lowry or Western blot. Afzal et al. (1), using RLPS prepared by the PCP method, found that the ELISA had a sensitivity of $94 \%$ with no false-positive reactors; $95.5 \%$ sensitivity with only $5 \%$ false-positive reactors (control groups 1 and 2) is reported here for the same antigen. However, when the different antigens were compared with sera from suspected animals (group 4), $28 \%$ of rams positive in either ELISA-HS or DGD did not contain sufficient antibody to PCP-RLPS to be considered positive. The slightly higher proportion of falsepositive reactors of HS (8\%) with respect to PCP-RLPS (5\%) cannot account for this result, as shown by the controls (data obtained by DGD). This same result also cannot be explained by the fact that, as discussed below, HS antigens detected antibody elicited by infection by $B$. melitensis, because all animals from group 4 were negative in the standard serological tests for smooth Brucella infection. On the other hand, since positive controls are defined in the work of Afzal et al. (1) and in ours as those animals from whose semen $B$. ovis was isolated, our results suggest that both semen culture and ELISA with PCP-RLPS underevaluate the actual proportion of rams infected by or exposed to $B$. ovis. This interpretation agrees with observations made by others on the value of the semen culture (18).

Although the ELISA (or DGD) with HS extracts was more sensitive than the PCP-RLPS ELISA in detecting $B$. ovis infection in rams, its ability to differentiate such an infection from $B$. melitensis infection was much lower. Since PCPRLPS reacted significantly with sera from $B$. melitensisinfected ewes (Fig. 3A), that observation can be partially accounted for by antigenic determinants shared by both smooth LPS and RLPS (lipid A and core). In addition, the presence of group $3 \mathrm{OM}$ proteins in HS extracts offers an explanation for the higher overlapping between $B$. melitensis- and B. ovis-infected animals (Fig. 3B), because they are shared by $B$. melitensis and rough Brucella species (28).

B. ovis whole cells, either intact $(31,10)$ or disintegrated by sonication (25), uncharacterized heat extracts $(27,34)$, or cell envelope deoxycholate crude extracts (6), have been used as antigens in ELISA for ram epididymitis. Our results, along with the fact that soluble antigens are shared by all Brucella species (8), show that ELISA with all those antigenic preparations cannot be assumed to be specific for $B$. ovis infection. Thus, the use of serological tests with such antigens could be misleading if applied to the specific evaluation of B.ovis in areas where $B$. melitensis occurs in sheep.

\section{ACKNOWLEDGMENTS}

We thank C. Longo for helping with statistical analysis of some of the data.

This research was supported by CAICYT grants 2910/83 and 0173/81. Fellowship support for J.I.R.-B. from the Asociación de Amigos de la Universidad de Navarra is gratefully acknowledged.

\section{LITERATURE CITED}

1. Afzal, M., R. P. Tengerdy, P. G. Squire, and R. P. Ellis. 1984. Characterization of Brucella ovis lipopolysaccharide and its use for diagnosis of ram epididymitis by enzyme-linked immunosorbent assay. J. Clin. Microbiol. 20:1159-1164.

2. Animal Health Reference Laboratory, Wallace Ville Animal Research Center. 1983. The complement fixation test for the diagnosis of $B$. ovis infection in rams. Animal Health Division report. N.Z. Vet. J. 31:157-160.

3. Blasco, J. M., R. Diaz, I. Moriyón, and M. D. Salvo. 1983. Evaluation of a radial immunodiffusion tests for diagnosing brucellosis in sheep and its possible value for differentiating infected from Brucella melitensis Rev.1 vaccinated sheep. Dev. Biol. Stand. 56:507-511.

4. Blood, D. C., O. M. Radostits, and J. A. Henderson. 1983. Veterinary medicine, 6th ed., p. 615-618. Baillière Tindall, London.

5. Burnette, W. N. 1981. Western blotting: electrophoretic transfer of proteins from sodium dodecyl sulfate-polyacrylamide gels to unmodified nitrocellulose and radiographic detection with antibodies and radioiodinated protein A. Anal. Biochem. 112: 195-203.

6. Chin, J. C. 1983. Comparison of different antigenic preparations for the detection of ovine serum antibodies against Brucella ovis by ELISA. Aust. Vet. J. 60:261-264.

7. Diaz, R., and N. Bosseray. 1973. Identification d'un composé antigénique spécifique de la phase rugueuse (R) des Brucella. Ann. Rech. Vet. 4:283-292.

8. Diaz, R., L. M. Jones, and J. B. Wilson. 1967. Antigenic relationships of Brucella ovis and Brucella melitensis. J. Bacteriol. 93:1262-1268.

9. Diaz, R., and D. Levieux. 1972. Rôle respectif en sérologie de la brucellose bovine des antigènes et des immunoglobulines $G_{1}$ et $\mathrm{G}_{2}$ dans les tests d'agglutination, de Coombs et au Rose Bengale ainsi que dans le phénomène de zone. C.R. Acad. Sci. Ser. D 274:1593-1596.

10. Dolley, P. M., F. Géral, J. L. Pellerin, A. Millon, and R. Lautié. 1982. L'épididymite contagieuse du bélier (infection à Brucella ovis). Note 1: mise au point de trois methodes de diagnostic sérologique. Rev. Med. Vet. (Toulouse) 133:187-195.

11. Galanos, C., O. Lüderitz, and O. Westphal. 1969. A new method for the extraction of $\mathrm{R}$ lipopolysaccharide. Eur. J. Biochem. 9:245-249.

12. Galanos, C., E. T. Rietschel, O. Lüderitz, and O. Westphal. 1972. Biological activities of lipid A complexed with bovine serum albumin. Eur. J. Biochem. 31:230-233.

13. Goldman, R. C., D. White, and L. Leive. 1981. Identification of outer membrane proteins, including known lymphocyte mitogens, as the endotoxin protein of Escherichia coli O111. J. Immunol. 127:1290-1294.

14. Hanson, R. S., and J. A. Phillips. 1981. Chemical composition, p. 328-364. In P. Gerhardt, R. G. E. Murray, R. N. Costilow, E. W. Nester, W. A. Wood, N. R. Krieg, and G. B. Phillips (ed.), Manual of methods for general bacteriology. American Society for Microbiology, Washington, D.C. 
15. Hawkes, R., E. Niday, and J. Gordon. 1982. A dot-immunobinding assay for monoclonal and other antibodies. Anal. Biochem. 119:142-147.

16. Heck, F. C., J. D. Williams, and J. Pruett. 1980. Interpretation of spectrophotometric absorbance values to define results of enzyme-linked immunosorbent assays. J. Clin. Microbiol. 11:398-401.

17. Jones, L. M., R. Diaz, and D. T. Berman. 1976. Endotoxic activity of rough organisms of Brucella species. Infect. Immun. 13:1638-1641.

18. Jones, L. M., G. Dubray, and J. Marly. 1975. Comparison of methods of diagnosis of Brucella ovis infection of rams. Ann. Rech. Vet. 6:11-12.

19. Laemmli, U. K. 1970. Cleavage of structural proteins during the assembly of the head of bacteriophage T4. Nature (London) 227:680-685.

20. Lamb, V. L., L. M. Jones, G. G. Schurig, and D. T. Berman. 1979. Enzyme-linked immunosorbent assay for bovine immunoglobulin subclass-specific response to Brucella abortus lipopolysaccharides. Infect. Immun. 26:240-247.

21. Lowry, O. H., N. J. Rosebrough, A. L. Farr, and R. J. Randall. 1951. Protein measurement by the Folin phenol reagent. J. Biol. Chem. 193:265-275.

22. Lugtenberg, B., and L. Van Alphen. 1983. Molecular architecture and functioning of the outer membrane of Escherichia coli and other gram negative bacteria. Biochim. Biophys. Acta 737:51-115.

23. Moriyón, I., and D. T. Berman. 1982. Effects of nonionic, ionic, and dipolar ionic detergents and EDTA on the Brucella cell envelope. J. Bacteriol. 152:822-828.

24. Myers, D. M., L. M. Jones, and V. M. Varela-Diaz. 1972. Studies of antigens for complement fixation and gel diffusion tests in the diagnosis of infections caused by Brucella ovis and other Brucella. Appl. Microbiol. 23:894-902.
25. Rahaley, R. S., S. M. Dennis, and M. S. Smeltzer. 1983. Comparison of the enzyme linked immunosorbent assay and complement fixation tests for detecting Brucella ovis antibodies in sheep. Vet. Rec. 112:467-470.

26. Ris, D. R. 1973. Is a Brucella ovis control scheme based on the complement fixation tests technically feasible? Proc. NZVA Sheep Society's 3rd Seminar, p. 77-79.

27. Ris, D. R., K. L. Hamel, and D. L. Long. 1984. Comparison of an enzyme-linked immunospecific assay (ELISA) with the cold complement fixation tests for the serodiagnosis of Brucella ovis infection. N.Z. Vet. J. 32:18-20.

28. Santos, J. M., D. R. Verstreate, V. Y. Perera, and A. J. Winter. 1984. Outer membrane proteins from rough strains of four Brucella species. Infect. Immun. 46:188-194.

29. Schurig, G. G., L. M. Jones, S. L. Speth, and D. T. Berman. 1978. Antibody response to antigens distinct from smooth lipopolysaccharide complex in Brucella infection. Infect. Immun. 21:994-1002.

30. Schurig, G. G., A. T. Pringle, and S. S. Breese, Jr. 1981. Localization of Brucella antigens that elicit a humoral immune response in Brucella abortus-infected cattle. Infect. Immun. 34:1000-1007.

31. Spencer, T. L., and G. W. Burgess. 1984. Enzyme linked immunosorbent assay for Brucella ovis specific antibody in ram sera. Res. Vet. Sci. 36:194-198.

32. Verstreate, D. R., M. T. Creasy, N. T. Caveney, C. L. Baldwin, M. W. Blab, and A. J. Winter. 1982. Outer membrane proteins of Brucella abortus: isolation and characterization. Infect. Immun. 35:979-989.

33. Warren, L. 1959. The thiobarbituric acid assay of sialic acids. J. Biol. Chem. 254:1971-1975.

34. Worthington, R. W., W. Weddell, and M. E. Penrose. 1984. A comparison of three serological tests for the diagnosis of $B$. ovis infection in rams. N.Z. Vet. J. 32:58-60. 